\title{
Factors Influencing the Uptake of Internet Connectivity in Meru Municipality, Meru County in Kenya
}

\section{Dominic M. Ndeke ${ }^{1}$ Stephen W. Luketero ${ }^{2}$ Chandi J. Rugendo ${ }^{3}$}

Department of Extra Mural Studies, University of Nairobi, Nairobi, Kenya. 'Email:mwirigidominic@gmail.com Tel: +254723985457

sEmail:john.rugendo@uonbi.ac.ke Tel:+254722836948

${ }^{2} S$ chool of Mathematics, University of Nairobi, Kenya.

${ }^{2}$ Email: sluketero@uonbi.ac.ke Tel: +254722882684

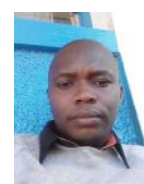

( Corresponding Author)

Abstract

The main objective of the study was to investigate the factors influencing the uptake of internet connectivity among Meru Municipality residents. This study, therefore, examined the following factors affecting the uptake of internet connectivity: Bandwidth speed, cost of internet, advertisement, and literacy levels. Data was analyzed using SPSS. One of the key findings was the high price of internet subscriptions was one of the most hindrance factors to internet accessibility by a majority of youths and even adults. The advertisement found as the second influencing factor, with the majority of respondents feeling much has to be done by internet providers to reach potential customers. Considering the population sample had 98 percent $\mathrm{O}$ level of education, and 98\% knew English or Kiswahili, Literacy levels discovered as the third influencing factor. Lastly, connection speed was the least factor. Hence, the study concluded that the high cost of the internet is one of the hindrance factors to internet penetration in Meru Municipality. Thus, an investigation should be initiated by internet service providers to determine the actual cost of internet provision across different towns as per the prevailing socio-economic climate in the area. Finally, the findings will be useful to the Ministry of Information and Technology, County Governments, Internet Service Providers, and other stakeholders who are aspiring to turn Kenya into a regional ICT hub and achieving Kenyans long term development plan of Vision 2030.

Keywords: Cost, Literacy, Bandwidth, Connectivity, Data, Internet, Router, Optical fiber, Advertisement.

Citation | Dominic M. Ndeke; Stephen W. Luketero; Chandi J. Rugendo (2020). Factors Influencing the Uptake of Internet Connectivity in Meru Municipality, Meru County in Kenya. Asian Journal of Social Sciences and Management Studies, 7(1): 39-52. History:

Received: 7 January 2020

Revised: 19 February 2020

Accepted: 23 March 2020

Published: 9 April 2020

Licensed: This work is licensed under a Creative Commons Attribution 3.0 License (oc)

Publisher: Asian Online Journal Publishing Group
Acknowledgement: All authors contributed to the conception and design of the study.

Funding: This study received no specific financial support

Competing Interests: The authors declare that they have no conflict of interests.

Transparency: The authors confirm that the manuscript is an honest, accurate, and transparent account of the study was reported; that no vital features of the study have been omitted; and that any discrepancies from the features of the study have been omitted
study as planned have been explained.

study as planned have been explained.
Ethical: This study follows all ethical practices during writing.

\section{Contents}

1. Background to the Study.

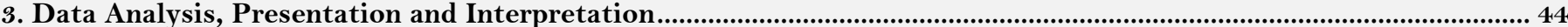

4. Summary of Findings, Discussions, Conclusions and Recommendations ....................................................................50

References. 


\section{Contribution of this paper to the literature}

This study contributes to existing literature by investigating the factors influencing the uptake of internet connectivity among Meru Municipality residents.

\section{Background to the Study}

Today the world has become a global village; people can communicate miles away each day through internet connectivity. The Internet is increasingly making its presence felt, not only playing an essential role in research and education but also serving as a catalyst to a country's socio-economic, cultural, and political development. It is therefore not a surprise that the Internet has become a development of the highest significance. Various connections are available across continents by different service providers (Titah \& Barki, 2006).

As of 2010, the world average Internet Penetration Rate (IPR) was about 28.8 percent. The United States had an IPR of about 77 percent. Other countries that had IPRs of less than 1 percent included Burkina Faso and Cambodia, each with an IPR of 0.5 percent. Afghanistan, Benin, Mauritania, and Turkmenistan also had very low IPRs of 1.5 percent, 1.8 percent, 1.0 percent, and 1.4 percent, respectively. Cuban official documents say that the country has an IPR of about 16 percent, but it's thought that the country's true IPR is closer to 1 to 3 percent. The countries that have the highest IPR include the Falkland Islands, Iceland, and Norway, with IPRs of 100 percent, 93.2 percent, and 90.9 percent, respectively. Other countries in Africa that had lots of Internet users as of 2011 included South Africa, with 6.8 million; Algeria, with about 4.7 million; and Sudan, with about 4.2 million. Algeria and South Africa had IPRs of almost 14 percent, and Sudan's was 9.3 percent. About 65 percent of Africa's Internet users in 2011 were from Nigeria, Egypt, or Morocco. Egypt had more Facebook users than Morocco and Nigeria, combined with about 9.4 million users. In 2007, less than 1 percent of Africans had access to broadband Internet (Simenda, 2009b).

Countries that have the lowest Internet access rates include Myanmar and East Timor, where 0.1 percent of the population has Internet access. Sierra Leone, where about 0.2 percent of the population does, and Bangladesh, the Central African Republic, Niger and the Democratic Republic of the Congo, where the Internet access rate is about 0.3 percent. More than 120 countries have an Internet Penetration Rate of less than 23.8 percent (Scott, 2006).

As of 2011 , the African country with the highest Internet penetration rate (IPR), the percentage of a country's population that has Internet access was Morocco, with 41.3 percent of the people, or about 13.2 million people, having access to the Internet. Nigeria had the most Internet users, about 44 million, and an IPR of 28.3 percent. Internet users in Nigeria accounted for about 37 percent of all Internet users in Africa. Egypt was second in terms of Internet users, with about 20 million, and had an IPR of about 24.5 percent. Egypt's Internet users accounted for about 16.9 percent of the total for Africa (Simenda, 2009a).

According to Government of Kenya (2012) There are 22 million mobile subscribers in Kenya. Prepaid accounts for $99 \%$ of the total mobile subscriptions, the number of internet users was estimated at 8.69 million, the number of internet/data subscriptions is 3.2 million, Broadband subscriptions increased from 18,626 subscribers in the previous quarter to 84,726 . A whopping $99 \%$ of the internet traffic in Kenya is done via mobile operators, meaning $3 \mathrm{G}$, Edge or GPRS. An estimate for those with internet access in Kenya is closing in on 9 million users, and at over $22 \%$ of the population (GoK, 2012).

The 2 nd CCK quarter report of 2011/2012 indicates the number of Internet users grew to 17.38 million as of December last year compared to 8.89 million users in the previous year, compared with the previous quarter, represents a growth of 21.55 percent. GoK statistics indicated 14.3 million Internet users in the previous quarter. GoK attributes the increase to intensified promotions on social media by mobile operators.

The use of the Internet has been on a rising trend, with the figure showing that 44.12 percent of the population has access to the Internet, with the majority accessing the Internet through mobile phones. According to the report, with the steady growth in mobile subscriptions, the increase in Internet usage is likely to continue as operators seek to leverage on new and emerging technologies to offer attractive packages aimed at garnering more subscribers to use this service. Kenya has a high penetration of mobile phones, standing at 71.3 percent, with 28.08 million mobile subscriptions in the country up from 26.49 million subscriptions recorded during the year $2010 / 2011$.

The report, however, shows the bandwidths in Kenya are underutilized. According to the GoK (2012), available international bandwidth has increased more than 25-fold, from 202,720.02 Mbps from December 2010 to $5,261,919 \mathrm{Mbps}$ in December 2011. The usage levels remain low, with only 1.01 percent under-utilization. The period saw the number of internet subscriptions rise to 6,152,687 Internet subscriptions from 5,422,009 during the previous period, representing a 13.48 percent increase.

Broadband subscriptions increased to 131,829 from 126,589 recorded during the previous period. Mobile data/Internet subscriptions on GPRS/EDGE and $3 \mathrm{G}$ recorded the highest portion of the total Internet/data subscriptions of 6.07 million subscriptions compared to 5.37 million subscriptions recorded during the previous period. Fixed fiber subscriptions recorded an upward trend with a growth of 66.97 percent during the period. Compared to the same period of the past year, an increase of 337.43 percent was recorded, which shows that the service is rapidly gaining ground and possibly consuming subscriptions from satellite service that have been on a declining trend.

Additionally, satellite subscriptions declined from 774 subscriptions in the previous period to 669 during the quarter under review. A reduction of 13.57 percent was recorded during the period as well as a 27.36 percent decline compared to the same period of the previous year (GoK, 2012).

In Kenya, more towns are getting connected to the recently launched Fibre optical inclusive of the Meru, which is in tandem with Kenya's Vision 2030 objective of improving the quality of life for the citizens of Kenya. This will transform employment markets, enhancing social infrastructure, securing good governance, and making Kenya an ICT hub in Africa. Table 1 provides a summary of internet subscriptions per operator in Kenya by Communication Commission of Kenya in 2012. 
Table-1. Internet Subscriptions per operator in Kenya by GoK (2012).

\begin{tabular}{l|l|c|c}
\hline No & Name of the Operator & Subscriptions & Market Share \\
\hline 1 & Safaricom & $2,977,584$ & 92.18 \\
\hline 2 & Airtel Kenya Ltd & 149,053 & 4.61 \\
\hline 3 & Telkom Orange & 77,668 & 2.40 \\
\hline 4 & Access Kenya & 7,512 & 0.23 \\
\hline 5 & Wananchi Telkom Ltd & 7,500 & 0.23 \\
\hline 6 & Kenya Data Networks & 7,451 & 0.17 \\
\hline 7 & Africa Online & 1,608 & 0.05 \\
\hline 8 & Flexible Bandwidth & 1,198 & 0.04 \\
\hline 9 & Swift Global & 1,133 & 0.03 \\
\hline 10 & Callkey Network Ltd & 800 & 0.02 \\
\hline 11 & Others & 516 & 0.01 \\
\hline 12 & Total & $3,232,023$ & 100 \\
\hline \multicolumn{2}{l|}{ Source: GoK (2012) }
\end{tabular}

\subsection{Statement of the Problem}

Meru is one of the towns in Kenya where internet subscriptions are low compared to other cities like Nakuru, Eldoret, Kisumu, with each having over 15,000 internet broadband subscriptions among other cities despite the availability of high-speed internet connections. Data available from Orange Telkom Meru Branch indicates a connection of 363 Units with 200 router connections and 163 live box connections, Meru Safaricom Retail Shop Data Bank (2013). Safaricom has over 2,200 internet connections in Meru Municipality, according to Meru Safaricom Retail Shop Data Bank (2013). Individuals, businesses, residential places, banks, government offices, hospitals, learning institutions, and other private entities have been connected to the internet, but the uptake has taken a low turn. Hence the researcher sought to investigate the factors influencing this slow uptake of internet connectivity by Meru Municipality residents as compared to other towns.

\subsection{Purpose of thestudy}

The purpose of the study was to investigate factors influencing the uptake of internet connectivity in Meru Municipality.

\subsection{Objectives of the Study}

The researcher's objectives of the study were:

i. To establish the influence of bandwidth speed on the uptake of internet connectivity in Meru Municipality.

ii. To assess the impact of advertisement on the uptake of internet connectivity in Meru Municipality.

iii. To determine the influence of the cost of the internet on the uptake of internet connectivity in Meru Municipality.

iv. To examine the influence of literacy levels on the uptake of internet connectivity in Meru Municipality.

\subsection{Research Questions}

The research study was guided by the following research questions:

i. How does bandwidth speed influence the uptake internet connectivity in Meru Municipality?

ii. How does advertisement influence the uptake of internet connectivity in Meru Municipality?

iii. How does cost of internet influence the uptake of internet connectivity in Meru Municipality?

iv. How does literacy level influence the uptake of internet connectivity in Meru Municipality?

\subsection{Significance of the Study}

The study would be relevant to the policymakers, especially the Ministry of Information and Technology, in assessing our steps toward achieving Kenya Vision 2030, which is our country's long-term development objective of making our country an ICT hub in Africa. It will also be necessary for measuring our achievements towards meeting the Millennium Development Goals.

Much of the information would also be vital to future academics, whereby the findings of this study will be used as a foundation base for further research.

\subsection{Delimitation of the Study}

The study covered Meru Municipality areas of Township, Gakoromone, and Kaaga. The researcher involved selected individuals connected to the internet. The findings of this study can also be generalized to larger populated towns like Kisumu or Nakuru, with a higher population of over 100,000 persons.

\subsection{Limitations of the Study}

The study was limited to several challenges; time to exhaustively cover all the Municipality area, also through the interview some of the respondents were unwilling to give some information for security reasons or answers they felt were too personal or difficult. The questionnaire design might have some inadequacy such that some information from the respondents might have been inaccurate.

\subsection{Assumptions of the Study}

The researcher assumed that majority of the Meru Municipality residents had a concrete idea of what internet connectivity entails.

The researcher assumed that the connected customers targeted as respondents participated fully in the 
research, and their responses were honest.

\section{Research Methodology}

\subsection{Introduction}

The chapter dealt with the procedures through which the research data was collected. To be more specific, the research design, the target population, sampling methods (procedures), and methods of data collection are keys areas that the researcher studied.

\subsection{Research Design}

A research design is a program to guide the researcher in the collection, analyzing, and interpreting observable facts (Kothari, 2003). The research study was undertaken by the use of a descriptive survey. A descriptive survey is a method of collecting information by interviewing or administering a questionnaire to a sample of individuals. This type of research attempts to describe such things as possible behavior, attitudes, and characteristics. Descriptive studies are not only restricted to fact-finding but may often result in the formulation of critical knowledge and solutions to significant problems (Kothari, 2003).

\subsection{Target Population}

The study covered Meru Municipality administrative area namely Township, Kaaga and Gakoromone areas with total households of 8,159 and a population of 27,303 persons covering an area of 8.7 Sq. KM. Sampling was done from a total population of 363 Orange internet connected units and 2,200 Safaricom connected individuals while the actual sample was got from individual connected persons among the connected population. The researcher therefore got the necessary information from them.

\subsection{Sampling Procedure}

Time and resources available to a researcher, the researcher should take a big sample as possible (Kothari, 2003). However, the sample size depends on other factors such as the number of variables in the study, type of the design, method of data analysis, and the size of the accessible population. For descriptive studies, $10 \%$ of the target population is enough (Kothari, 2003). Hence on this basis, the researcher used 20 connected units from a population of 200 units connected through routers and a sample of 16 connected units through live boxes $(10 \%$ of the 200 and 163 units respectively). An example of 100 individuals was used as respondents from Safaricom (from a population of 2,200 Wi-fi routers connected individuals) to be distributed across the three administrative units of Gakoromone, Township and Kaaga areas (Kothari, 2003). The Sample was distributed as follows, if Pi represents proportion of population in stratum $\mathrm{i}$, and $\mathrm{n}$ represents the total sample size, the number of element selected from stratum i, is n.pi, (Kothari, 2003). This was calculated as follows; Sample size $(n)=100$ to be drawn from a population size $(\mathrm{N})=27,303$ divided into three strata sizes. The actual respondents from the sample was determined by getting the list of all numbered connected units from Telkom Orange and Safaricom Data Banks and randomly picking the twenty-second connected individual in the list as per Table 2.

\begin{tabular}{c|c|c}
\hline & Table-2. Sample size. \\
\hline Area & Formula & Sample Size \\
\hline Township (N1) & $4,156 / 27,303 * 100$ & 15 \\
\hline Kaaga (N2) & $11,689 / 27,303 * 100$ & 43 \\
\hline Gakoromone (N3) & $11,458 / 27,303 * 100$ & 42 \\
\hline Total & & 100 \\
Source: Ndeke (2013).
\end{tabular}

\subsection{Methods of Data Collection}

Both primary and secondary data were used for this research study. Primary data was collected through the administration of questionnaires. The questions were both open and closed. Some of the questionnaires were selfadministered but the researcher was also available to clarify any items that will be unclear to the respondents. Besides, some of the questionnaires were left to the respondents to fill later if they were unavailable to be collected on agreed date. Questionnaires were appropriate in gathering much information from respondents on the uptake of internet connectivity in Meru municipality.

\subsection{Piloting}

Piloting of the research document was carried out to determine the validity and reliability of the research instrument.

\subsubsection{Validity of the Research Instrument}

Validity is the degree to which a tool measures what it purports to measure. Validity is concerned with whether the findings are really what they appear to be about. The instrument validity was ensured through the continuous expert advice of my supervisors who are well versed in research. 
Asian Journal of Social Sciences and Management Studies, 2020, 7(1): 39-52

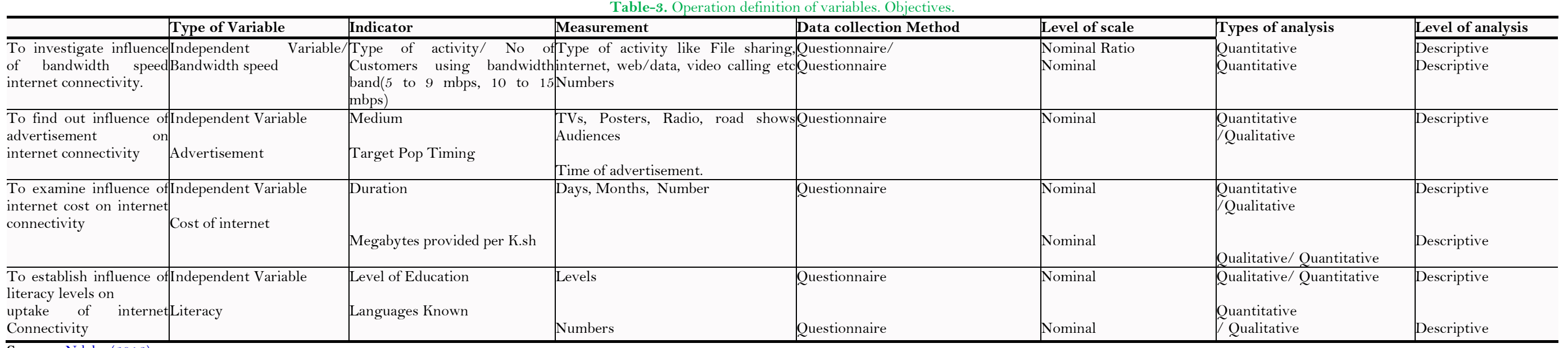

Source : Ndeke (2013). 


\subsubsection{Reliability}

Reliability is a measure of the degree to which a research instrument yields consistent results on data after repeated trials. A reliable tool is one that produces consistent results when used more than once to collect data from the sample randomly drawn from the sample population.

In the research study, a pilot study was carried out by administering the questionnaire to selected few individuals to determine the reliability of the tool. To test the reliability of the instrument, the researcher used spilt-half technique. The research instrument was split into two subtests, one consisting of odd-numbered items/questions and the other made of all even-numbered items. The score of all odd-numbered and evennumbered items of the responses in the pilot study was computed separately. The odd-numbered scores for all items were correlated with the even-numbered scores using the Pearson product correlation coefficient. The results of the Pearson Product correlation co-efficient turned out to be above 0.75 , and hence the instrument was highly reliable.

\subsection{Operation Definition of Variables}

Factors influencing the uptake of internet connectivity in Meru Municipality definition of variables as shown in Table 3.

\section{Data Analysis, Presentation and Interpretation}

\subsection{Introduction}

This chapter deals with data analysis, presentation, and interpretation of the study findings, the findings were based on all data collected, including primary as well as secondary data collected from the field. The main objective was to investigate the factors influencing the uptake of internet connectivity among Meru Municipality residents. The research objectives covered included advertisement, cost of internet, literacy levels, and bandwidth speed. Data were analyzed using SPSS. The findings were then presented in tables, frequencies, and percentages.

\subsection{Questionnaire Return Rate}

A total of One hundred and thirty-six (136) questionnaires were distributed to the respondents across three administrative units of Township, Kaaga, and Gakoromone. Table 4 below represents the questionnaire return rate by Meru Municipality residents.

\begin{tabular}{l|c} 
Table-4. Questionnaire return rate by Meru Municipality residents (2013). \\
\hline Questionnaire return rate & No. \\
\hline Total questionnaire given & 136 \\
\hline Questionnaire returned & 105 \\
\hline Percentage & $76 \%$ \\
\hline Source: Ndeke (2013).
\end{tabular}

Out of this, a total of 105 questionnaires were returned, representing a 76 percent return rate, which was adequate for analysis.

\subsection{Descriptive Analysis on the Uptake of Internet Connectivity by Meru Municipality Residents}

The study sought to determine the demographic characteristics of the respondents based on gender, educational level and language spoken and the findings are as presented in Table 5.

\begin{tabular}{c|c|c}
\multicolumn{2}{c}{ Table-5. demographic characteristics of Meru municipality residents by gender distribution (2013). } \\
\hline Sex & Frequency & Percent \\
\hline Male & 46 & 43.8 \\
\hline Female & 59 & 56.2 \\
\hline Total & 105 & 100 \\
\hline Source: Ndeke (2013). &
\end{tabular}

Majority of the respondents $59(56.2 \%)$ were female with while male was $46(43.8 \%)$; hence the respondents gender no wide variance. The study sought to investigate the respondent's level of education as shown in Table 6.

Table-6. Education level of Meru municipality resident's (2013).

\begin{tabular}{l|c|c}
\hline Education Level & Frequency & Percent \\
\hline Primary level & 3 & 2.9 \\
\hline Secondary level & 31 & 29.5 \\
\hline Diploma Level & 41 & 39.0 \\
\hline University level & 30 & 28.6 \\
\hline Total & 105 & 100.0 \\
\hline Source: Ndeke (2013). &
\end{tabular}

Of the respondents sampled, the majority (41) had a diploma level in education with 39.0 percent, while the primary level of education had the lowest respondents with (3) 2.9 percent. The secondary level had (31)29.5 percent while the university level had (30) 28.6 percent, indicating that the majority of the respondents were literate enough to know what internet connectivity entails.

The study sought to determine languages spoken by respondents, as shown in Table 7. 


\begin{tabular}{c|c|c}
\multicolumn{2}{c}{ Table-7. Languages spoken by Meru municipality residents (2013). } \\
\hline Language & Frequency & Percent \\
\hline English or Kiswahili & 103 & 98.1 \\
\hline Foreign Languages & 2 & 1.9 \\
\hline Total & 105 & 100.0 \\
\hline Source: Ndeke (2013).
\end{tabular}

(103) 98.1 percent of the respondents were either familiar with English or Kiswahili, while only two respondents were familiar with foreign languages, mainly French, as Table 7 indicates.

The study sought to determine devices used by the respondent to access the internet, as shown in Table 8 .

Table-8. Devices used to access the internet by Meru municipality residents (2013).

\begin{tabular}{c|c|c}
\hline Type of device & Frequency & Percent \\
\hline Computer & 6 & 5.7 \\
\hline Mobile Phone & 40 & 38.1 \\
\hline Both (Computer \& Mobile) & 59 & 56.2 \\
\hline Total & 105 & 100.0 \\
\hline Source: Ndeke (2013). &
\end{tabular}

A majority of the respondents used both computers and their mobile phones to connect to the internet with (59) 56.2 percent while (40) 38.1 percent used mobile phones while the rest (6) 5.7 percent used computers to surf hence the majority of respondents used both computers and mobile phones to access the internet as Table 8. indicates.

The study sought to determine megabytes subscribed and their cost by the respondents, as shown in Table 9.

Table-9. Megabytes cost (Subscriptions) of internet among Meru municipality residents.

\begin{tabular}{l|c|c}
\hline Megabytes Prices & Frequency & Percent \\
\hline O-49MB for less than KES 100 & 44 & 41.9 \\
\hline 50-99MB for KES 100- 150 & 36 & 34.3 \\
\hline 100-499MB for KES 150-500 & 19 & 18.1 \\
\hline 500-1000MB for KES 500-1000 & 6 & 5.7 \\
\hline Total & 105 & 100.0 \\
\hline Source: Ndeke (2013).
\end{tabular}

Source: Ndeke (2013)

A majority of the respondents utilized a lower denomination Megabytes of less than KES 100 with a (44) 41.9 percent, (36) 34.3 percent subscribed to MB of between KES 100-150, (19)18.1 percent subscribed to cost of between 150-500 K.sh while (6) $5.7 \%$ subscribed to the cost of between K.sh 500 and K.sh 1000 indicating that lower denomination subscriptions were in great use as shown in Table 9.

The study sought to find out the respondent's access to the internet, as shown in Table 10.

Table -10. Access to internet by Meru municipality residents (2013).

\begin{tabular}{l|c|c}
\multicolumn{2}{c}{ Table -10. Access to internet by Meru municipality residents (2013). } \\
\hline Frequency of access & Frequency & Percent \\
\hline Once a Month & 3 & 2.9 \\
\hline Once a week & 17 & 16.2 \\
\hline Several times a week & 40 & 38.1 \\
\hline Everyday & 34 & 32.4 \\
\hline Several times a day & 11 & 10.5 \\
\hline Total & 105 & 100.0 \\
\hline Source: Ndeke (2013). &
\end{tabular}

A majority of residents accessed internet several times per week with (40) 38.1 percent, (34) 32.4 percent accessed every day, (17)16.2 accessed once per week, (11)10.5 percent accessed several times a day while (3)2.9 percent accessed once a month clearly showing that majority of residents accessed the internet every day and several times a week as shown in Table 10.The study sought to find out respondent opinion on the cost of internet as shown in Table 11.

Table-11. Respondent opinion on the cost of internet by Meru municipality residents (2013).

\begin{tabular}{c|c|c}
\multicolumn{2}{c}{ Table-11. Respondent opinion on the cost of internet by Meru municipality residents (2013). } \\
\hline Cost Level & Number & Percentage \\
\hline Low cost & 4 & 3.8 \\
\hline Medium Cost & 58 & 55.2 \\
\hline High Cost & 43 & 41.0 \\
\hline Total & 105 & 100.0 \\
\hline
\end{tabular}

The majority of the respondent viewed the cost of internet cost as medium with (58) 55.2 percent, (43) 41.0 percent regarded the price as high while (4) 3.8 percent viewed the cost as low as shown by Table 11 .

The study sought to investigate hours spent online by the respondent, as shown in Table 12. 
Table-12. Hours spent online by Meru municipality residents (2013).

\begin{tabular}{|c|c|c|}
\hline Hours Spent & Frequency & Percent \\
\hline Less than five hours & 40 & 38.1 \\
\hline Six to Fifteen hours & 41 & 38.0 \\
\hline Over fifteen hours & 24 & 22.9 \\
\hline Total & 105 & 100.0 \\
\hline
\end{tabular}

The majority of the respondents spent zero to fifteen hours, representing an (81) 76 percent. The rest (24)22.9 percent spent over fifteen hours, clearly showing heavy use of the internet was minimal, as shown in Table 12.

\begin{tabular}{c|c|c}
\multicolumn{2}{c|}{ Table-13. Meru municipality resident's connection speed opinion provided by internet service providers (2013). } \\
\hline Speed Level & Frequency & Percent \\
\hline Very low & 5 & 4.8 \\
\hline Low & 5 & 4.8 \\
\hline Medium & 53 & 50.5 \\
\hline High & 31 & 29.5 \\
\hline Very high & 11 & 10.5 \\
\hline Total & 105 & 100.0 \\
\hline Source: Ndeke (2013) & &
\end{tabular}

The study sought the respondent's opinion on speed provided by the internet service provider, as shown in Table 13.

Majority of the respondents viewed the speed provided by their internet providers at medium level with (53) 50.5 percent, (31) 29.5 percent viewed the rate as high, (11)10.5 percent viewed the speed as very high while (5) 4.8 percent viewed the speed as low and very as shown in Table 13.

The research study sought to assess respondent's opinion on speed satisfaction level as shown in Table 14.

Table-14. Respondent opinion on speed satisfaction levels by Meru municipality residents (2013).

\begin{tabular}{c|c|c}
\hline Opinion & Frequency & Percent \\
\hline Yes & 70 & 66.7 \\
\hline No & 35 & 33.3 \\
\hline Total & 105 & 100.0 \\
\hline Source: Ndeke $(2013)$ & & \\
\hline
\end{tabular}

Source: Ndeke (2013)

(70 )66.7 percent of the respondents were satisfied with the speed. In comparison with (35), 33.3 percent viewed the rate as not satisfactory, clearly illustrating that majority of Meru residents were happy with the speed, as shown in Table 14.

The study sought to determine respondent use of the internet, as shown in Table 15.

Table-15. Meru Municipality residents use of internet (2013)

\begin{tabular}{c|c|c}
\multicolumn{3}{c}{ Table-15. Meru Municipality residents use of internet (2013). } \\
\hline Use of internet & Frequency & Percent \\
\hline Own entertainments & 53 & 50.5 \\
\hline School or work purposes & 52 & 49.5 \\
\hline Total & 105 & 100.0 \\
\hline Source: Ndeke (2013)
\end{tabular}

Almost an equal number used the internet for own entertainment and school or work purposes with (53) 50.5 percent for entertainment while (52)49.5 for school or work purposes.

The study sought to determine the respondent's age distribution, as shown in Table 16.

Table-16. Meru Municipality residents age distribution (2013).

\begin{tabular}{l|c|c}
\hline Age distribution & Frequency & Percent \\
\hline 10- 18 Years & 16 & 15.2 \\
\hline $19-25$ Years & 31 & 29.5 \\
\hline 26-30 Years & 32 & 30.5 \\
\hline $31-35$ Years & 15 & 14.3 \\
\hline Over 35 Years & 11 & 10.5 \\
\hline Total & 105 & 100.0 \\
\hline Source: Ndeke (2013)
\end{tabular}

About (32) 30.5 percent of the respondents were in the age bracket of 26- 30 years, (31) 29.5 percent were in the age bracket of 19-25 years, (16) 15.2 percent were in the age bracket of 10-18 years and (15) 14.3 percent were in the age bracket of 31-35 years while (11)10.5 percent were over 35 years clearly indicating access to the internet was across the different age groups as shown in Table 16. The study sought to find out how the respondents learnt about internet connection shown in Table 17 .

Table-17. How Meru Municipality residents learnt about internet connection (2013).

\begin{tabular}{|c|c|c|}
\hline Medium & Frequency & Percent \\
\hline TV advert & 57 & 54.3 \\
\hline Posters Advert & 32 & 30.5 \\
\hline Road show advert & 4 & 3.8 \\
\hline Friends & 12 & 11.4 \\
\hline Total & 105 & 100.0 \\
\hline
\end{tabular}

Source: Ndeke (2013) 
The majority of the respondent learned about the internet through TV advert with (57) 54.3 percent, (32) 30.5 percent through posters, (12) 11.4 percent through friends, and (4)3.8 percent through roadshows as shown in Table 17.

The study sought to know whether the advertisement appealed to the respondent or not, as shown in Table 18.

Table-18. Opinion on advertisement appeal by Meru municipality residents (2013).

\begin{tabular}{c|c|c}
\hline Residents Opinion & Frequency & Percent \\
\hline Yes & 89 & 84.8 \\
\hline No & 16 & 15.2 \\
\hline Total & 105 & 100.0 \\
\hline Source: Ndeke $(2013)$ & &
\end{tabular}

Source: Ndeke (2013)

Of the respondents sampled, (89) 84.8 percent were appealed by the advertisement while (16) 15.2 percent were not attracted by the ad, a clear indication that there was an opportunity for more publicity, as shown in Table 18. The study sought to determine respondent opinion on the factors influencing the uptake of internet connectivity as shown in Table 19.

Table-19. Opinion on the factors influencing the uptake of internet connectivity by Meru municipality residents (2013).

\begin{tabular}{c|c|c}
\hline Residents Opinion & Frequency & Percent \\
\hline Low Bandwidth speed & 21 & 20.0 \\
\hline Lack of advertisement & 18 & 17.1 \\
\hline High Cost & 44 & 41.9 \\
\hline High literacy requirement & 22 & 21.0 \\
\hline Total & 105 & 100.0 \\
\hline
\end{tabular}

Source: Ndeke (2013)

Of the respondents sampled (44), 41.9 viewed the high cost of the internet as one of the significant factor influencing internet connectivity, (22) 21 percent high literacy requirement, (21) 20 percent low bandwidth speed and (18) 17.1 percent lack of advertisement, a clear indication that cost was one of the significant factor influencing internet connectivity in Meru Municipality as shown in Table 19.

\subsection{Cross Tabulation of Tables}

i. To examine the influence of literacy levels on the uptake of internet connectivity among the Meru municipality residents

Table-20. A cross tabulation of respondent's education levels versus respondent use of internet.

\begin{tabular}{|c|c|c|c|c|}
\hline \multirow{3}{*}{$\begin{array}{l}\text { Education level } \\
\text { Primary Level }\end{array}$} & \multicolumn{4}{|c|}{ Respondent's use of internet } \\
\hline & \multicolumn{4}{|c|}{ Own entertainment School or work purposes Total } \\
\hline & Count & 3 & $\mathrm{O}$ & 3 \\
\hline & \% within education level & $100.0 \%$ & $0.0 \%$ & $100.0 \%$ \\
\hline \multirow[t]{2}{*}{ Secondary Level } & Count & 26 & 5 & 31 \\
\hline & \% within education level & $83.9 \%$ & $16.1 \%$ & $100.0 \%$ \\
\hline \multirow[t]{2}{*}{ Diploma Level } & Count & 16 & 25 & 41 \\
\hline & $\%$ within education level & $39.0 \%$ & $61.0 \%$ & $100.0 \%$ \\
\hline \multirow[t]{2}{*}{ University level } & Count & 8 & 22 & 30 \\
\hline & \% within education level & $26.7 \%$ & $73.3 \%$ & $100.0 \%$ \\
\hline \multirow[t]{2}{*}{ Total } & Count & 53 & 52 & 105 \\
\hline & \% within education level & $50.5 \%$ & $49.5 \%$ & $100.0 \%$ \\
\hline
\end{tabular}

Education levels affected respondent use of the internet, a (3)100\% with a primary level of education utilized the internet for own entertainment like chat rooms, playing computer games, and downloading music or video. (26) $83.9 \%$ with a secondary level of education used the internet for own entertainment while (5) $16.1 \%$ used the internet for school or work purposed like sending or receiving emails, word processing, and research. (16) $39 \%$ with diploma level used internet for own entertainment while (25) $61 \%$ used for school or work purposes. (8) 26.7 $\%$ with university-level used internet for entertainment while (22) $73.3 \%$ used it for school or work purposes, as shown in Table 20. From this, we conclude that once the education level of respondents rises, much of the internet use is either for work or school purposes.

Table-21. Respondent literacy level * internet use chi-square test.

\begin{tabular}{c|c|c|c}
\hline Statistic Test & Value & df & Asymp. Sig. (2 sided) \\
\hline Pearson Chi-square & 25.728 & 3 & .000 \\
\hline Likelihood ratio & 28.518 & 3 & .000 \\
\hline Total cases & 105 & & \\
\hline
\end{tabular}

Source: Ndeke (2013).

Our p-value is 0.00 , which is a very low probability making our variables dependent and thus concluding that education levels tie very much with what each respondent does when on the internet, since as one education level advances much of the internet use is either for work or school purposes as shown in Table 21. 
Table-22. A cross tabulation of Respondent age versus use of the internet.

\begin{tabular}{|c|c|c|c|c|}
\hline & \multicolumn{4}{|c|}{ Respondent's use of internet } \\
\hline & & Own entertainment & School or work purposes & Total \\
\hline \multirow[t]{2}{*}{$10-18$ years } & Count & 15 & 1 & 16 \\
\hline & \% within respondent age & $93.8 \%$ & $6.3 \%$ & $100.0 \%$ \\
\hline \multirow[t]{2}{*}{$19-25$ years } & Count & 16 & 15 & 31 \\
\hline & \% within respondent age & $51.6 \%$ & $48.4 \%$ & $100.0 \%$ \\
\hline \multirow[t]{2}{*}{ 26-30years } & Count & 14 & 18 & 32 \\
\hline & \% within respondent age & $43.8 \%$ & $56.3 \%$ & $100.0 \%$ \\
\hline \multirow[t]{2}{*}{$31-35$ years } & Count & 5 & 10 & 15 \\
\hline & \% with respondent age & $33.3 \%$ & $66.7 \%$ & $100.0 \%$ \\
\hline \multirow[t]{2}{*}{ Over 35 years } & Count & 3 & 8 & 11 \\
\hline & \% within respondent age & $27.3 \%$ & $72.7 \%$ & $100.0 \%$ \\
\hline \multirow[t]{2}{*}{ Total } & Count & 53 & 52 & 105 \\
\hline & \% within respondent age & $50.5 \%$ & $49.5 \%$ & $100.0 \%$ \\
\hline
\end{tabular}

Source: Ndeke (2013)

The majority of the respondents in the age bracket of 10-18 years used the internet for entertainment purposes with (15) 93. $8 \%$ against (1) $6.3 \%$ for school or work purposes. For 19- 25 age bracket, (16)51.6\% used for entertainment while (15)48.4\% used for school or work purposes. For $26-30$ age brackets, (14) $43.8 \%$ used the internet for entertainment while (18)56.3\% used for school or work purposes, as shown in Table 22. For 31-35 age brackets (5), $33.3 \%$ used the internet for entertainment while (10) $66.7 \%$ used for work or school purposes. For those over 35 years, (3)72.7\% used internet for school or work purposes while only (8)27.3\% used the internet for entertainment. Therefore, we can conclude that the younger generation used the internet for entertainment purposes, while the older generation utilized the internet for school or work purposes.

Table-23. Respondent age ${ }^{*}$ use of internet chi-square test.

\begin{tabular}{c|c|r|r}
\hline Statistical Test & Value & df & Asymp. Sig. (2 sided) \\
\hline Pearson Chi-square & 16.714 & 4 & .002 \\
\hline Likelihood ratio & 19.281 & 4 & .001 \\
\hline Total cases & 105 & & \\
\hline Source: Ndeke (2013).
\end{tabular}

Our p-value is 0.002 , which is a very low probability making our variables dependent and thus concluding that respondent age ties very much with what each respondent does when on the internet as the younger generation uses the internet for entertainment. In comparison, the older generation uses the internet for work or school purposes, as shown in Table 23.

ii. To assess the influence of advertisement on the uptake of internet connectivity among Meru Municipality residents.

Table-24. A cross tabulation of how the respondent learnt versus age of the respondent.

\begin{tabular}{c|c|c|c|c|r}
\hline Age & TV advert & Posters adv. & Road show & Adv Friends & Total \\
\hline 10-18 years Count & 6 & 7 & 0 & 3 & 16 \\
\hline \% within respondent age & $37.5 \%$ & $43.8 \%$ & $0 \%$ & $18.8 \%$ & $100.0 \%$ \\
\hline 19-25 years Count & 21 & 5 & 1 & 4 & 31 \\
\hline \% within respondent age & $67.7 \%$ & $16.1 \%$ & $3.2 \%$ & $12.9 \%$ & $100.0 \%$ \\
\hline 26-30 years Count & 17 & 12 & 2 & 1 & 32 \\
\hline \% within respondent age & $53.1 \%$ & $37.5 \%$ & $6.3 \%$ & $3.1 \%$ & $100.0 \%$ \\
\hline 31-35 years Count & 6 & 6 & 1 & 2 & 15 \\
\hline \% within respondent age & $40.0 \%$ & $40.0 \%$ & $6.7 \%$ & $13.3 \%$ & $100.0 \%$ \\
\hline Over 35 years Count & 7 & 2 & 0 & 2 & 11 \\
\hline \% within respondent age & $63.6 \%$ & $18.2 \%$ & $0.0 \%$ & $18.2 \%$ & $100.0 \%$ \\
\hline Total Count & 57 & 32 & 4 & 12 & 105 \\
\hline \% within respondent age & $54.3 \%$ & $30.5 \%$ & $3.8 \%$ & $11.4 \%$ & $100.0 \%$ \\
\hline
\end{tabular}

Source: Ndeke (2013).

For the 10-18 age bracket category, the majority of the respondents learned about the internet through posters advert at (7) $43.8 \%$ followed by TV advert at (6)37.5\%. For $19-25$ years bracket, majority of the respondent learned about the internet through TVs advert at (21) 67.7\% followed by posters at (5)16.1\%. For 26-30 years bracket majority of the respondent learned about the internet through TV advert at (17)53.1\% followed by posters at (12) $37.5 \%$. For 31-35 years bracket majority of the respondent learned about the internet through TVs and posters advert tying at (12) $40.0 \%$, as shown in Table 24 . Those over 35 years discovered through TV advert at (7) $63.6 \%$. We conclude, therefore, the majority of the respondents learned about the internet through TVs and Posters advert at (57)54.3\% and (32) $30.5 \%$ respectively.

Table-25. How the respondent learnt *age of respondent chi-square test.

\begin{tabular}{c|c|c|c}
\hline Statistical Test & Value & df & Asymp. Sig. (2 sided) \\
\hline Pearson Chi-square & 12.247 & 12 & .426 \\
\hline Likelihood ratio & 14.149 & 12 & .291 \\
\hline Total cases & 105 & & \\
\hline Source: Ndeke (2013).
\end{tabular}

Our p-value is 0.426 , which is a very high probability making our variables independent and thus concluding that the respondent age does not tie with how the respondent learned about internet connection, as shown in Table 25. 
Table-26. A cross tabulation of how the respondent learnt versus advertisement appeal.

\begin{tabular}{l|c|c|c}
\hline \multicolumn{3}{c}{ Advertisement appeal to respondent } \\
\hline How the respondent learnt & Yes & No & Total \\
\hline TV advert & 50 & 7 & 57 \\
\hline$\%$ within how the respondent learnt & $87.7 \%$ & $12.3 \%$ & $100.0 \%$ \\
\hline Posters advert & 29 & 3 & 32 \\
\hline$\%$ within how the respondent learnt & $90.6 \%$ & $9.4 \%$ & $100.0 \%$ \\
\hline Road show advert & 2 & 2 & 4 \\
\hline$\%$ within how the respondent learnt & $50.0 \%$ & $50.0 \%$ & $100.0 \%$ \\
\hline Friends & 8 & 4 & 12 \\
\hline$\%$ within how the respondent learnt & $66.7 \%$ & $33.3 \%$ & $100.0 \%$ \\
\hline Total & 89 & 16 & 105 \\
\hline$\%$ within how the respondent learnt & $84.8 \%$ & No & $100.0 \%$ \\
\hline Source: Ndeke $(0013)$ & & & \\
\hline
\end{tabular}

Source: Ndeke (2013).

In Table 26 above, (50) $87.7 \%$ of the respondents who learned about internet connection through TVs advert were appealed by it, (29) $90.6 \%$ of the respondents who learned about internet connection through posters were appealed by it, and (8) $66.7 \%$ of the respondents who learned about internet connection through friends were appealed. We conclude, therefore, that majority of the respondents were attracted by the advertisement to connect to the internet by whatever marketing medium.

iii. To determine the influence of cost of internet on the uptake of internet connectivity among Meru

Municipality residents.

Table-27. A cross tabulation of megabytes cost versus hours spent online.

\begin{tabular}{l|c|c|c|c}
\hline \multicolumn{5}{c}{ Hours spent online } \\
\hline Megabytes Cost & Less than 5 hrs & $\mathbf{6 - 1 5}$ hrs & Over 15 hrs & Total \\
\hline O-49MB for < KES 100 & 25 & 17 & 2 & 44 \\
\hline \% within megabytes cost & $56.8 \%$ & $38.6 \%$ & $4.5 \%$ & $100.0 \%$ \\
\hline 50-99MB for KES 100-150 Count & 11 & 17 & 8 & 36 \\
\hline \% within megabytes cost & $30.6 \%$ & $47.2 \%$ & $22.2 \%$ & $100.0 \%$ \\
\hline 100-499 for KES 150-500 & 2 & 6 & 11 & 19 \\
\hline \% within megabytes cost & $10.5 \%$ & $31.6 \%$ & $57.9 \%$ & $100.0 \%$ \\
\hline 500-1000MB for KES 500-1000 Count & 2 & 1 & 3 & 6 \\
\hline \%within megabytes cost & $33.3 \%$ & $16.7 \%$ & $50.7 \%$ & $100 \%$ \\
\hline Total & 40 & 41 & $\mathbf{2 4}$ & $\mathbf{1 0 5}$ \\
\hline \%within megabytes cost & $38.1 \%$ & $39.0 \%$ & $22.9 \%$ & $100.0 \%$ \\
\hline Source: Ndeke (2013). & & &
\end{tabular}

Majority of the respondents who subscribed to less than 50MB spent less than five hours online with (25) $56.8 \%,(17) 47.2 \%$ of the respondents who subscribed for $50-100 \mathrm{MB}$ spent six to fifteen hours online,(11) $57.9 \%$ of the respondents who subscribed 100-499 MB spent over fifteen hours online and (3) $50.7 \%$ of respondents who subscribed for 500-1000MB spent over fifteen hours as shown in Table 27. We conclude, therefore, that respondents spent more hours online as the data bundle subscription increased.

\begin{tabular}{c|c|c|c}
\multicolumn{5}{c}{ Table-28. Megabytes cost $*$ hours spent online chi-square test. } \\
\hline Statistical Test & Value & df & Asymp. Sig. (2 sided) \\
\hline Pearson Chi-square & 28.671 & 6 & .000 \\
\hline Likelihood ratio & 29.541 & 6 & .000 \\
\hline Total cases & 105 & & \\
\hline Source: Ndeke (2013).
\end{tabular}

Our p-value is 0.00 , which is a very low probability making our variables dependent and thus concluding that megabytes prices (subscribed) ties very much with hours spent online by the respondents with higher subscriptions respondent spending more time online as shown in Table 28.

iv. To examine the influence of bandwidth speed on uptake of internet connectivity among Meru Municipality residents.

Table-29. A cross tabulation of connection speed versus access to interne.

\section{Access to internet by respondent}

\begin{tabular}{|c|c|c|c|c|c|c|}
\hline \multicolumn{7}{|c|}{$\begin{array}{l}\text { Speed Once a month Once a week Several times a week Everyday Several times a day } \\
\text { Total }\end{array}$} \\
\hline Very low Count & $\mathrm{O}$ & 2 & $\mathrm{O}$ & 2 & 1 & 5 \\
\hline \% within speed & $0 \%$ & $40.0 \%$ & $0 \%$ & $40.0 \%$ & $20.0 \%$ & $100.0 \%$ \\
\hline Low Count & 2 & 1 & 1 & $\mathrm{O}$ & 1 & 5 \\
\hline$\%$ within speed & $40.0 \%$ & $20.0 \%$ & $20.0 \%$ & $\mathrm{O}$ & $20.0 \%$ & $100.0 \%$ \\
\hline Medium Count & $\mathrm{O}$ & 7 & 19 & 21 & 6 & 53 \\
\hline \% within speed & $\mathrm{O}$ & $13.2 \%$ & $35.2 \%$ & $39.6 \%$ & $11.3 \%$ & $100.0 \%$ \\
\hline High Count & $\mathrm{O}$ & 4 & 14 & 10 & 3 & 31 \\
\hline \% within speed & $\mathrm{O} \%$ & $12.9 \%$ & $45.2 \%$ & $32.3 \%$ & $9.7 \%$ & $100.0 \%$ \\
\hline Very high Count & 1 & 3 & 6 & 1 & $\mathrm{O}$ & 11 \\
\hline \% within speed & $9.1 \%$ & $27.3 \%$ & $54.5 \%$ & $9.1 \%$ & $0 \%$ & $100.0 \%$ \\
\hline Total Count & 3 & 17 & 40 & 34 & 11 & 105 \\
\hline \% within speed & 2.9 & 16.2 & 38.1 & 32.4 & 10.5 & $100.0 \%$ \\
\hline
\end{tabular}


Majority of the respondent who viewed connection speed as average accessed internet several times a week with (19) 35.2\% while others who accessed the internet every day with (21) $39.6 \%$. Those who viewed connection speed as high accessed internet several times a week with (14) $45.2 \%$ while others who accessed the internet every day with (10) $32.3 \%$. The majority of the respondents who viewed connection speed as very high accessed the internet several times a week with (6) $54.5 \%$, as shown in Table 29. We conclude then the majority of respondents accessed the internet several times a week and viewed speed connection as medium and high.

\begin{tabular}{c|c|c|c}
\multicolumn{4}{c}{ Table-30. Connection speed * access to internet chi-square test. } \\
\hline Statistical Test & Value & df & Asymp. Sig. (2 sided) \\
\hline Pearson Chi-square & 41.385 & 16 & .000 \\
\hline Likelihood ratio & 30.594 & 16 & .015 \\
\hline Total cases & 105 & & \\
\hline Source: Ndeke (2013).
\end{tabular}

Our p-value is 0.00 , which is a very low probability making our variables dependent and thus concluding that connection speed ties very much with access to the internet by respondents, as shown in Table 30.

Table-31. A Cross tabulation of connection speed versus respondent speed satisfaction.

\begin{tabular}{l|c|c|c}
\hline & \multicolumn{3}{c}{ Respondent speed satisfaction } \\
\hline Connection speed & Yes & No & Total \\
\hline Very low & 3 & 2 & 5 \\
\hline$\%$ within connection speed & $60.0 \%$ & $40.0 \%$ & $100.0 \%$ \\
\hline Low & 2 & 3 & 5 \\
\hline$\%$ within connection speed & $40.0 \%$ & $60.0 \%$ & $100.0 \%$ \\
\hline Medium & 33 & 20 & 53 \\
\hline \% within connection speed & $62.3 \%$ & $37.7 \%$ & $100.0 \%$ \\
\hline$\%$ within connection speed & 23 & 8 & 31 \\
\hline Very high & $74.2 \%$ & $25.4 \%$ & $100.0 \%$ \\
\hline$\%$ within connection speed & 9 & 2 & $\mathbf{1 1}$ \\
\hline Total & $81.8 \%$ & $18.2 \%$ & $100.0 \%$ \\
\hline$\%$ within connection speed & 70 & 35 & 105 \\
\hline Sour & $66.7 \%$ & $33.3 \%$ & $100.0 \%$ \\
\hline
\end{tabular}

Source: Ndeke (2013).

Out of the 53 respondents who viewed the speed connection as medium, (33) $62.3 \%$ viewed the speed as satisfactory while (20) 37.7 percent viewed the speed on the negative side. Out of 31 respondents who viewed the speed as high, $74.2 \%$ that is 23 respondents confirmed the speed to be satisfactory while (8)25.4\% viewed the speed as not adequate, as shown in Table 31 . We conclude, therefore, that the respondents who saw the connection speed as medium and high were comfortable with it, that is, a total of 56 respondents.

\section{Summary of Findings, Discussions, Conclusions and Recommendations \\ 4.1. Summary of Findings}

Out of the total of 105 respondents, The Majority of the respondents were females with 56.2 percent, while males represented 43.8 percent. To get a picture of literacy levels among the respondents, results on education levels indicated that Majority had diploma level in education with 39.0 percent. In comparison, the primary level of education had the lowest respondents, with 2.9 percent. The secondary level had 29.5 percent, while the university level had 28.6 percent. On languages spoken, 98.1 percent of the respondents were either familiar with English or Kiswahili, while only two respondents were familiar with foreign languages, mainly French.

The results also indicated that a majority of the respondents used both computers and their mobile phones to connect to the internet with 56.2 percent. In comparison, 38.1 percent used mobile phones, while the rest 5.7 percent used machines to access the internet. On the cost of internet and megabytes subscribed by respondents, the results analyzed indicated that a majority of the respondents utilized a lower denomination Megabytes of less than KES 100 with a percentage of 41.9 percent, 34.3 percent subscribed to MB of between KES 100-150, 18.1 percent subscribed to cost of between 150-500 K.sh. In contrast, 5.7 subscribed to the cost of between K.sh 500 and K.sh 1000. When asked about their general view on the value of the internet, the Majority of the respondent viewed the cost of internet cost as medium with 55.2 percent, 41.0 percent viewed the price as high while 3.8 percent viewed the cost as low.

On how often they accessed the internet, a majority of residents accessed the web several times per week, with 38.1 percent. 32.4 percent accessed every day,16.2 accessed once per week, 10.5 percent accessed several times a day while 2.9 percent accessed once a month while the Majority of the respondents spent between zero to fifteen hours representing 76 percent. The rest 22.0 percent spent over fifteen hours.

On the connection speed available, the majority of the respondents viewed the rate provided by their internet providers at medium level with 50.5 percent, 29.5 percent viewed the pace as high, 10.5 percent viewed the speed as very high. In comparison, 4.8 percent saw the rate as low and very. Besides, 66.7 percent of the respondents were satisfied with the speed, while 33.3 percent viewed the speed as not satisfactory.

On internet usage by the respondents, results indicate that almost an equal number used the internet for own entertainment and school or work purposes with 50.5 percent for entertainment while 49.5 for school or work purposes. The results investigated the age bracket of the respondent and discovered that about 30.5 percent of the respondents were in the age bracket of 26- 30 years, 29.5 percent were in the age bracket of 19-25 years, 15.2 percent were in the age bracket of 10-18 years, and 14.3 percent were in the age bracket of 14.3 percent while 10.5 percent were over 35 years.

On how the respondent learned about their current internet connection, the majority of the respondents 
learned about the internet through TV advert with 54.3 percent, 30.5 percent through posters, 11.4 percent through friends, and 3.8 percent through roadshows. Besides, of the respondents sampled, 84.8 percent were appealed by the advertisement, while 15.2 percent were not attracted by the ad. When asked about which factor the respondent thought influenced this uptake of the internet,41.9 viewed the high cost of the internet as one of the significant factor affecting internet connectivity, 21 percent high literacy requirement, 20 percent low bandwidth speed, and 17.1 percent lack of advertisement.

\subsection{Discussions of Findings}

Of the respondents sampled, Male represented $56.2 \%$ while females represented $43.8 \%$ hence no significant variation. Therefore, we conclude that gender did not have much effect on internet connectivity and thus depended on individuality. To show the relationship between variables, cross-tabulation and Pearson square were calculated.

\subsubsection{Objective One: Literacy Levels and Internet Connectivity}

Education levels were cross-tabulated with the use of the internet; the results indicated that: $100 \%$ with a primary level of education utilized the internet for own entertainment like chat rooms, playing computer games, and downloading music or video. 83.9 percent with a secondary level of education used the internet for own entertainment. In comparison, 16.1 percent used the internet for school or work purposed like sending or receiving emails, word processing, and research. $39 \%$ with diploma level used the internet for their own entertainment while $61 \%$ used for school or work purposes. $26.7 \%$ with university-level used internet for entertainment while $73.3 \%$ used it for school or work purposes. From this, we conclude that once the education level of respondents rises, much of the internet use is either for work or school purposes. Besides, 98.1 percent were familiar with either English or Kiswahili, which is in tandem with what search engines like Google offer their contents in. Also, a chisquare test revealed a low probability hence concluding that education levels tie very much with what each respondent does when on the internet. This finding goes well with Rogers (1995) who noted that the internet has mainly diffused in urban areas among the comparatively wealthy and educated considering Meru Municipality is a metropolitan area.

\subsubsection{Objective Two: Advertisement and Internet Connectivity.}

A cross-tabulation between the advertisement medium through which respondents learned about internet connection and age revealed that; for 10-18 years bracket majority of the respondents learned about the internet through posters advert at $43.8 \%$ followed by TV advert at $37.5 \%$. For $19-25$ years bracket majority of the respondent learned about the internet through TVs advert at $67.7 \%$ followed by posters at $16.1 \%$, in $26-30$ years bracket majority of the respondent learned about the internet through TVs advert at $53.1 \%$ followed by posters at $37.5 \%$, in 31-35 years bracket majority of the respondent learned about the internet through TVs and posters advert tying at $40.0 \%$. Those over 35 years discovered through TV advert at $63.6 \%$. The majority of the respondents learned about the internet through TVs and Posters advert at 54.3\% and $30.5 \%$ respectively. A chisquare test revealed a high probability and thus concluding that the respondent's age does not tie with how the respondent learned about the internet connection. We can conclude that the purpose of advertising is to create awareness of the advertised product and provide information that will assist the consumer in making a purchase decision. The relevance of advertising as a promotional strategy, therefore, depends on its ability to influence consumers not only to purchase but to continue to repurchase and eventually develop- brand loyalty (Mittal, 2001).

\subsubsection{Objective 3: Cost of Internet Connection}

A cross-tabulation between the number of megabytes subscribed and hours spent online revealed that, Majority of the respondents who subscribed to less than 50MB spent less than five hours online with $56.8 \%, 47.2 \%$ of the respondents who subscribed for $50-100 \mathrm{MB}$ spent six to fifteen hours online, $57.9 \%$ of the respondents who subscribed to 100-499 MB spent over fifteen hours online and $50.7 \%$ of respondents who subscribed for $500-$ $1000 \mathrm{MB}$ spent over fifteen hours. We therefore conclude that respondents spent more hours online as the data bundle subscription increased. The chi-square test also revealed a low probability hence finding that the cost of that megabyte (subscribed) ties very much with hours spent online by the respondents. We also conclude that the Majority of lower age brackets accept to lower data bundles mainly for chat room purposes. From these findings, we conclude that the high cost of the internet is a hindrance to internet subscription, which is much shared with GoK (2012), which found that $28 \%$ of Kenyans cited the cost of internet subscription as a significant hindrance.

\subsubsection{Objective Four: Internet Speed Connection.}

On internet speed connection, the majority of the respondents viewed the speed provides by their internet providers at medium level with 50.5 percent, 29.5 percent viewed the rate as high, 10.5 percent viewed the speed as very high. In comparison, 4.8 percent saw the speed as low and very low. Hence the majority were comfortable with the rate, which can be attributed to the presence of $3 \mathrm{G}$ network provided by some of the internet service providers. The presence of high-speed could be attributed to the presence of fiber optic, which provides a more top speed packet. A concept shared by Mittal (2001) since fiber optic services starts as high as 10 or 20 Megabytes per second, with top-tier packages offering 50 Megabytes per second.

\subsection{Conclusions}

Internet connectivity is affected by many factors, including Connection speed available, cost of internet, advertisement provided, and literacy levels in a specific area. According to our research findings, the high price of internet subscriptions was identified as one of the most hindrance factor to internet accessibility by the majority of youths and even adults. The advertisement was found as the second influencing factor, with the majority of respondents feeling much has to be done by internet providers to reach potential customers. Considering the population sample had 98 percent O level of education, and 98\% knew English or Kiswahili, Literacy levels was 
found as the third influencing factor. Lastly, connection speed was perceived as the least factor which can be attributed to the presence of high-speed packet area around Meru Municipality. Hence it can be authoritatively concluded; that the high cost of the internet is one of the significant hindrance factors to the internet penetration in Meru Municipality.

\subsection{Recommendations}

1. A study should be initiated by internet service providers to determine the actual cost of internet provision across different towns, which shall be pegged to the prevailing socio-economic climate in the area.

2. Various internet providers should re-engineer their advertisement systems to capture many potential customers.

3. New areas should be mapped and included in high packet transmission sites by internet providers.

\section{References}

Government of Kenya. (2012). Communication of Kenya industry performance report, Nairobi Kenya. Retrieved from https://orcid.org/0000-0003-0055-7231.

Kothari, C. R. (2003). Research methodology (2nd ed.). New Delhi: KK Grupta of new Age international (P) Ltd.

Meru Safaricom Retail Shop Data Bank. (2013). Retrieved from https://orcid.org/0000-0003-0055-7231.

Mittal, K. (2001). Internet traffic growth, analysis of trends and predictions (pp. 1-16). The Haworth Political Press: New York.

Ndeke, M. (2013). Factors affecting uptake of internet connectivity in Meru Municipality, Meru County Kenya. Retrieved from https://orcid.org/0000-0003-0055-7231.

Rogers, E. M. (1995). Diffusion of innovations (4th ed.). New York: Free Press.

Scott, W. (2006). Broadband and unbundling regulations in OECD countries, Working Paper 06-16, June 2006. Washington, D.C: AEI Brooking Joint Center for Regulatory Studies.

Simenda, K. (2009a). Electronic mobile government in Africa: Progress made and challenges ahead. Addis Ababa, Ethiopia.

Simenda, K. (2009b). Electronic mobile government in Africa: Progress made and challenges ahead. Addis Ababa, Ethiopia. Retrieved from http://www.unpan.org/emgkr_africa.

Titah, R., \& Barki, H. (2006). E-government adoption and acceptance: A literature review. International Journal of Electronic Government Research, 2(3), 23-57.Available at: https://doi.org/10.4018/jegr.2006070102. 